\title{
OPTIC, ELECTROOPTIC AND DIELECTRIC PROPERTIES OF NOVEL ANTIFERROELECTRIC LIQUID CRYSTAL COMPOUNDS
}

\author{
PONTUS JÄGEMALM ${ }^{\mathrm{a}}$, JAN P. F. LAGERWALL ${ }^{\mathrm{a}}$, ANDERS \\ DAHLGREN $^{\mathrm{a}}$, LACHEZAR KOMITOV ${ }^{\mathrm{a}}$, AVTAR S. MATHARU ${ }^{\mathrm{b}}$, \\ CHRISSIE GROVER ${ }^{\mathrm{b}}$, FATHI GOUDA ${ }^{\mathrm{a}, \mathrm{c}}$ AND ABDUL A. KUTUB ${ }^{\mathrm{c}}$, \\ a Department of Microelectronics and Nanoscience, Chalmers University \\ of Technology, S-412 96 Göteborg, Sweden; 'Department of chemistry, \\ The Nottingham Trent University, Clifton Lane, Nottingham NG11 \\ 8NS, England; 'Umm Al-Qura University, P.O. Box 6427, Makkah, \\ Saudi Arabia;.
}

The optic, electrooptic and dielectric spectroscopy characterisation of novel four-ring thiophene-based chiral esters comprising suitably 5,5'disubstituted 2,2'-bithiophene (antiferroelectrics) is reported. The two compounds exhibit interesting hysterises in their phase sequences, and we show that even whole phases (e.g. their relatively wide ferri-phases) may be suppressed by the surface interactions in thin cells.

Keywords: antiferroelectric; ferrielectric; ferroelectric; dielectric spectroscopy; pitch;

\section{INTRODUCTION}

Due to continual development of the tristate switching phenomenon, there is a strong demand for liquid crystalline compounds which exhibit the $\mathrm{SmC}_{\gamma}{ }^{*}$ and $\mathrm{SmC}_{\mathrm{A}} *$ phases ${ }^{[1-3]}$. The latter participate in tristate switching which is deemed as the switching from the antiferroelectric state to one of 


\section{P. JÄGEMALM et al.}

two field-induced ferroelectric states (corresponding to positive and negative electric fields, respectively) via a very sharp electric field threshold.

A structural survey of such compounds reveals that the majority possess a calamitic molecular architecture comprising the 1-methylheptyl moiety as a terminal group. However, due to many of the preconceptions associated with liquid crystallinity and molecular geometry there are very few compounds reported in the literature which both show strong deviation from the classical molecular architecture and $\mathrm{SmC}^{*}, \mathrm{SmC}_{\gamma}{ }^{*}$ and $\mathrm{SmC}_{\mathrm{A}} *$ phases ${ }^{[4,5]}$.

In 1998, Matharu et al. ${ }^{[6]}$, reported the synthesis and textural investigation of a novel partially non-linear compound $\left(\mathbf{A 4}, \mathrm{R}=\mathrm{C}_{12} \mathrm{H}_{25}\right)$ comprising suitably di-substituted bithiophene as the molecular core. Despite its bent or non-linear molecular architecture, A4 exhibits the $\mathrm{SmC}^{*}$ and $\mathrm{SmC}_{\mathrm{A}}$ * phase types as well as a moderately wide $\mathrm{SmC}_{\gamma}{ }^{*}$ phase.

We now report further extensive studies: electro-optical response, pitch and dielectric spectroscopy on A4 and the newly synthesised CG50 $\left(\mathrm{R}=\mathrm{C}_{10} \mathrm{H}_{21}\right)$ in order to confirm initially the textural study reported by Matharu et al. ${ }^{[6]}$, and more importantly to gain an insight to the molecular processes involved with such rather unusual structures.

\section{SYNTHESIS}

The synthetic pathway for the preparation of A4 and CG50 is summarised in figure 1. The synthetic procedure for CG50 is analogous to the one for $\mathrm{A} 4$, which has been reported previously ${ }^{[6]}$.

Bithiophene (1) was prepared using the nickel-catalysed crosscoupling methodology reported by Tamao et al.$^{[7]}$, whereby, the Grignard reagent of 2-bromothiophene was coupled with 2-bromothiophene to afford (1) in high yield (85\%). Friedel-Crafts acylation of (1) with the appropriate alkanoyl chloride, catalysed by titanium(IV) tetrachloride, gave the intermediate acyl-compounds which were reduced immediately (Huang-Minlon) to the alkyl-compounds (2a and $\mathbf{2 b})$. Lithiation (1.6M $\mathrm{BuLi},-78^{\circ} \mathrm{C}$ ) of compounds (2a and $\mathbf{2 b}$ ) followed by solid carbon dioxide quench, furnished the desired thiophene-based carboxylic acids (3a and $\mathbf{3 b}$ ). DCC esterification ${ }^{[8]}$ of compounds (3a and $\mathbf{3 b}$ ) with $(S)$ - 
1-methylheptyl 4'-hydroxybiphenyl-4-carboxylate $(\mathbf{4})^{[9]}$ produced the required chiral bithiophene esters (A4 and CG 50).

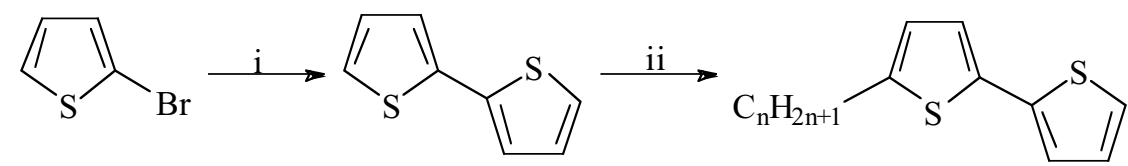

(1)

(2a, $\mathrm{n}=10 ; \mathbf{2 b}, \mathrm{n}=12$ )

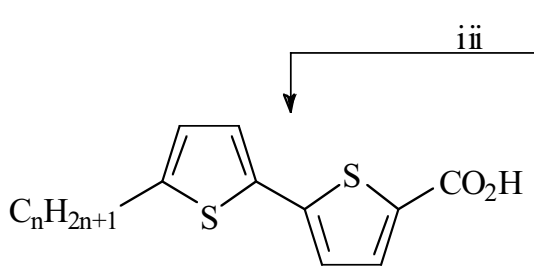

$(\mathbf{3 a}, \mathrm{n}=10 ; \mathbf{3 b}, \mathrm{n}=12)$
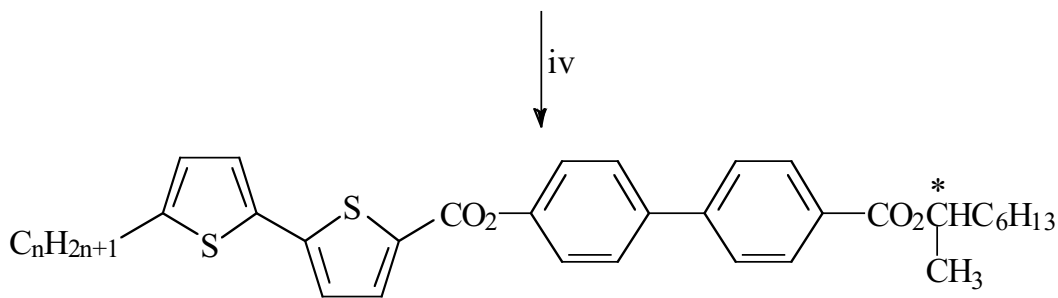

$\left(\mathbf{C G ~ 5 0 , ~} \mathrm{n}=\mathrm{C}_{10} \mathrm{H}_{25} ; \mathbf{A 4}, \mathrm{n}=\mathrm{C}_{12} \mathrm{H}_{25}\right)$

i. $\quad\left[\left(\mathrm{C}_{6} \mathrm{H}_{5}\right)_{2} \mathrm{PCH}_{2} \mathrm{CH}_{2} \mathrm{CH}_{2}\left(\mathrm{C}_{6} \mathrm{H}_{5}\right)\right] \mathrm{NiCl}_{2}$, ether

ii. a. $\mathrm{TiCl}_{4}, \mathrm{C}_{\mathrm{n}} \mathrm{H}_{2 \mathrm{n}} \mathrm{COCl}, \mathrm{CH}_{2} \mathrm{Cl}_{2} ;$ b. $\mathrm{NH}_{2} \mathrm{NH}_{2} \cdot \mathrm{H}_{2} \mathrm{O}, \mathrm{KOH}$, diethylene glycol

iii. $\quad$ a. $1.6 \mathrm{M} \mathrm{BuLi},-78^{\circ} \mathrm{C}, \mathrm{N}_{2} ;$ b. $\mathrm{CO}_{2}, \mathrm{H}^{+}$

iv. (4), Dicyclohexylcarbodiimide (DCC), dimethylaminopyridine, $\mathrm{CH}_{2} \mathrm{Cl}_{2}$

FIGURE 1: The reaction scheme for the two compounds A4 and CG-50.

\section{PHASE SEQUENCE}

The phase sequence for the two materials are (as measured by DSC on heating):

CG-50: $\mathrm{SmX}^{*} \bullet 86.7 \bullet \mathrm{SmI}_{\mathrm{A}} * \bullet 96.9 \bullet\left(\mathrm{SmC}_{\mathrm{A}}{ }^{*} \bullet-\bullet \mathrm{SmC}_{\gamma}{ }^{*} \bullet-\bullet \mathrm{SmC}^{*}\right)$

$\cdot 131.0 \cdot \mathrm{SmA}^{*} \cdot 144.2 \cdot$ iso $/\left({ }^{\circ} \mathrm{C}\right)$

A4: $\quad \mathrm{SmX}^{*} \bullet 83.6 \bullet \mathrm{SmI}_{\mathrm{A}}^{*} \bullet 92.0 \bullet\left(\mathrm{SmC}_{\mathrm{A}} * \bullet-\bullet \mathrm{SmC}_{\gamma}^{*} \bullet-\bullet \mathrm{SmC}^{*}\right)$

$\cdot 132.9 \cdot \mathrm{SmA}^{*} \cdot 138.9 \cdot$ iso $/\left({ }^{\circ} \mathrm{C}\right)$ 


\section{P. JÄGEMALM et al.}

where the transitions written within brackets have been detected by means of optical microscopy and by measurements reported below.

\section{ELECTROOPTIC MEASUREMENTS}

We have studied the spontaneous polarisation $\mathrm{P}_{\mathrm{S}}$ and molecular tilt $\theta$ as a function of temperature, shown for CG-50 in figure 2. Both show a plateau in the temperature range of the $\mathrm{SmC}_{\gamma}{ }^{*}$ phase (in this $10 \mu \mathrm{m}$ cell approx. 110 to $120^{\circ} \mathrm{C}$ ), the origin of which is not yet clear. The existence of the $\mathrm{SmC}^{*}, \mathrm{SmC}_{\gamma}{ }^{*}$ and $\mathrm{SmC}_{\mathrm{A}}{ }^{*}$ phases was evidenced by the electrooptical and current response as well as by the voltage dependence of $\mathrm{P}_{\mathrm{S}}$ in these phases. As can be seen from figure $3(\mathrm{a}), \mathrm{P}_{\mathrm{S}}$ in the $\mathrm{SmC}_{\gamma}{ }^{*}$ phase saturates with the applied field first at the value of approximately $1 / 3$ of the value of $\mathrm{P}_{\mathrm{S}}$ at high fields. In the $\mathrm{SmC}_{\mathrm{A}}{ }^{*}$ phase, $\mathrm{P}_{\mathrm{S}}$ exhibits a clear threshold behaviour with a threshold of more than $10 \mathrm{~V} / \mu \mathrm{m}$. The switching in the $\mathrm{SmI}_{\mathrm{A}}{ }^{*}$ phase has a more complex character, which is shown by the electrooptic and current response depicted in figure 3(b). More than three switching states can be seen in the electrooptic reponse which relate to changes in the current response. Below the $\mathrm{SmI}_{\mathrm{A}}{ }^{*}$ phase there is another higher order smectic phase which exhibits a linear electrooptic response. We belive that this phase might be an orthogonal phase, but additional studies are necessary to prove it.

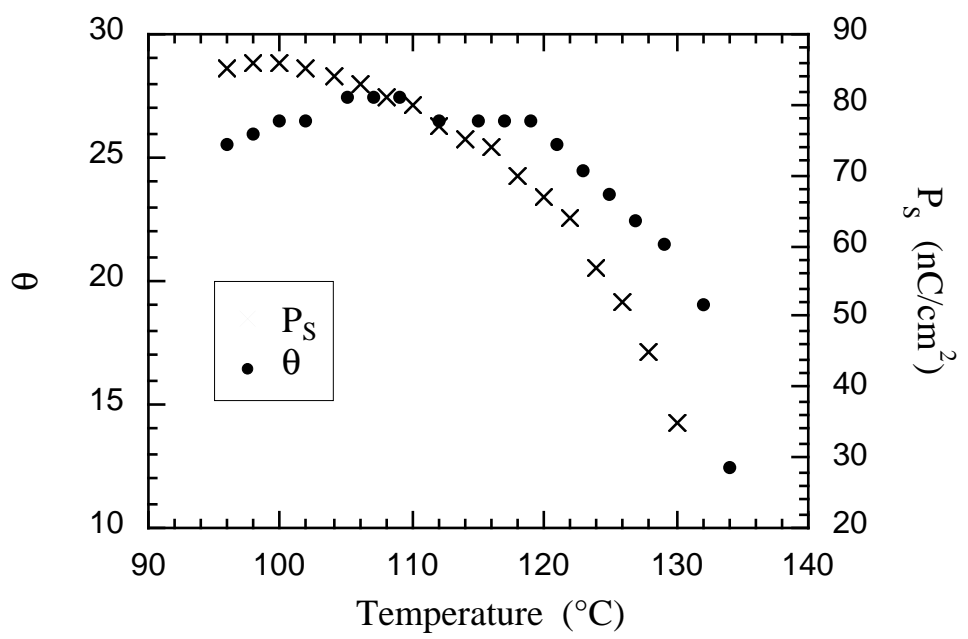

FIGURE 2: Spontaneous polarisation $\mathrm{P}_{\mathrm{S}}$ and molecular tilt angle $\theta$ as a function of temperature for the material CG-50. 


\section{OPTIC AND DIELECTRIC PROPERTIES OF NOVEL AFLCs}

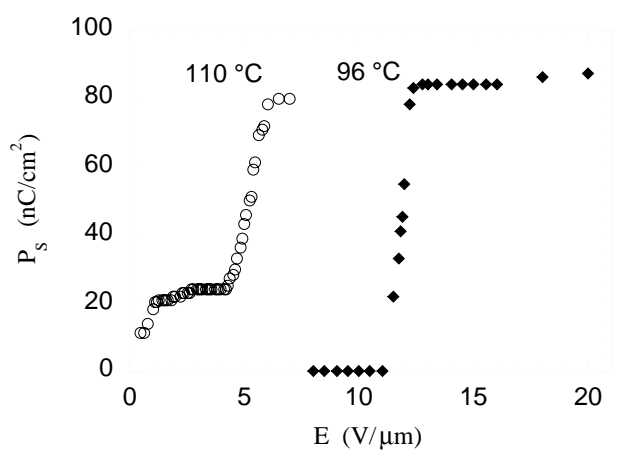

(a)

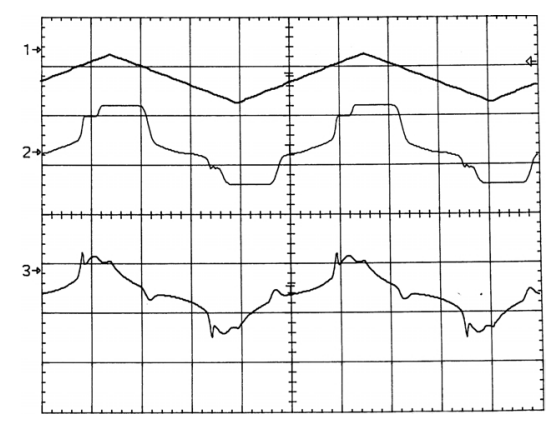

(b)

FIGURE 3: (a) Spontaneous polarisation $\mathrm{P}_{\mathrm{S}}$ as a function of the applied field for the material CG-50 in the $\mathrm{SmC}_{\gamma}{ }^{*}\left(110{ }^{\circ} \mathrm{C}\right)$ and $\mathrm{SmC}_{\mathrm{A}} *\left(96{ }^{\circ} \mathrm{C}\right.$ ) phase. (b) Electrooptic (curve 2) and current (curve 3 ) respons as a function of the applied field (curve 1) in the $\mathrm{SmI}_{\mathrm{A}}{ }^{*}$ phase of CG-50 (arb. units).

\section{PITCH MEASUREMENTS}

In order to measure the pitch, we analysed the selective reflection from free-standing films of the two materials. Free-standing films (or freely suspended films) are highly interesting for investigations of various liquid crystal phases since they provide possibilities to escape from boundary effects, which at least for thin conventional samples may affect the behaviour of the pitch, as well as the phase sequence itself ${ }^{[10,11]}$.

In this study, we also have to ensure that the film is sufficiently thick to give selective reflection, which in practice means that the film thickness has to be a minimum of about ten times the pitch $(d \geq 10 p)$. (The film preparation is described in detail in references ${ }^{[12,13]}$.) The films are normally formed with the helix standing perpendicular to the film surfaces (homeotropic helix geometry) and thus with the smectic layers parallel to the boundaries, a geometry which gives possibility for measurements of selective reflection of light propagating along the helix axis. To measure the transmittance of the film as a function of the wavelength, we inserted the films in a Shimadzu 3101PC spectrophotometer.

Figure 4 shows the length of the pitch as a function of temperature for free-standing films of the materials A4 and CG-50, where each point has 


\section{P. JÄGEMALM et al.}

been obtained by analysing a spectrum at the specific temperature. The spectra, which were obtained on increasing the temperature, show more or less distinct dips where the selective reflection takes place. The pitch in the $\mathrm{SmC}_{\mathrm{A}}{ }^{*}$ phase seems to diverge for low temperatures, at the same time as the reflection becomes weaker and weaker. In the $\mathrm{SmC}^{*}$ phase, there is a general increase in the pitch with increasing temperatures, but at temperatures close to the SmA* phase, the pitch starts to decrease again.

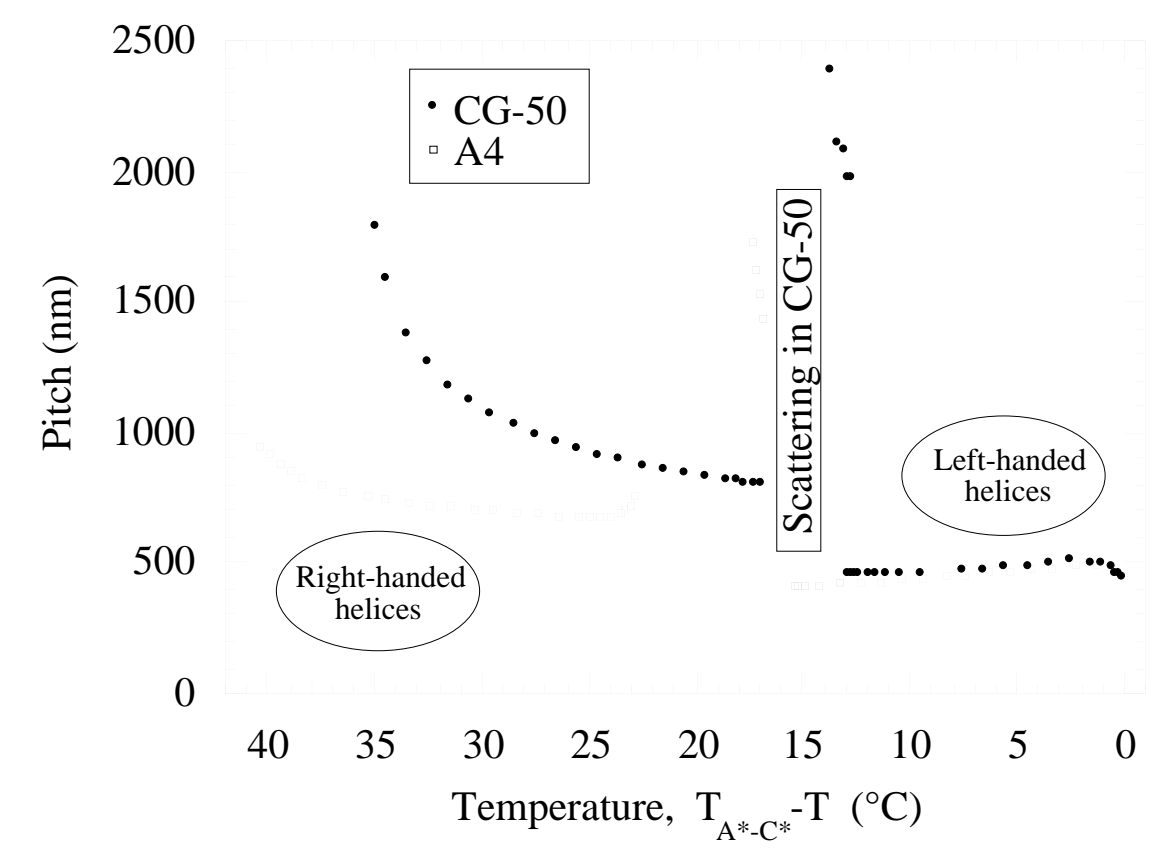

FIGURE 4: Pitch (not compensated for $n$ ) as a function of temperature measured in free-standing films of the materials A4 and CG-50. The film thicknesses are approximately $20 \mu \mathrm{m}$. There is a temperature interval where also the material A4 scatters light, but due to limited space it has been omitted in this figure.

In-between the $\mathrm{SmC}_{\mathrm{A}}{ }^{*}$ phase and the $\mathrm{SmC}^{*}$ phase in figure 4, there is an interesting region which contains at least the $\mathrm{SmC}_{\gamma}{ }^{*}$ phase and possibly also other $\mathrm{SmC}^{*}$ sub-phases. In going from the $\mathrm{SmC}_{\mathrm{A}}{ }^{*}$ phase across the phase transition, we first observe a strongly scattering state where the light over a broad wavelength range is scattered from the film. For slightly higher temperatures within the range of the $\mathrm{SmC}_{\gamma}{ }^{*}$ phase, the scattering shown in figure 4 disappears and a reflection at long 


\section{OPTIC AND DIELECTRIC PROPERTIES OF NOVEL AFLCs}

wavelengths becomes visible. As the temperature increases, the pitch corresponding to this reflection decreases from approximately $2500 \mathrm{~nm}$ to $2000 \mathrm{~nm}$. There is a small interval where this reflection at long wavelengths is present as well as the reflection coming from the $\mathrm{SmC}^{*}$ phase, which can be interpreted as coexistence of the $\mathrm{SmC}_{\gamma}{ }^{*}$ phase and the $\mathrm{SmC}^{*}$ phase. In a thin film spectrum, the previously described scattering state as well as this long pitch reflection is missing. The plausible reason for the absence of a long pitch reflection is that the films were too thin to give any detectable reflection in the long pitch limit (note that the film thickness only corresponds to a few full turns in this limit) even if, in principle, the helix might also be absent due to the surface forces which affect the pitch more strongly in a thin film.

To find the handedness of the pitch, we analysed the transmittance of circularly (or almost circularly) polarised light through the film. Since the liquid crystal helix only reflects light with the same handedness as the pitch, the handedness can be determined as the one which gives lowest transmittance at the reflection wavelength. The measurements show that the pitch is right-handed in the $\mathrm{SmC}_{\mathrm{A}}{ }^{*}$ phase, changes sign somewhere in the $\mathrm{SmC}_{\gamma}{ }^{*}$ phase(s) and is left-handed in the $\mathrm{SmC}^{*}$ phase.

\section{DIELECTRIC SPECTROSCOPY MEASUREMENTS}

The dielectric response of the compounds was investigated using an HP4192A dielectric bridge. All results described below were obtained in planar orientation.

\section{Behaviour in thick $(50 \mu \mathrm{m})$ cells}

On cooling, both materials feature normal $\mathrm{SmA}^{*}$ and $\mathrm{SmC}^{*}$ spectra, while the $\mathrm{SmC}_{\gamma} *$ phase is distinguished by a surprisingly weak absorption. On heating, a strong low-frequency absorption, not present in the cooling runs, appears in the vicinity of the $\mathrm{SmC}_{\gamma}{ }^{*}-\mathrm{SmC}^{*}$ transition (figure 5). This absorption has the characteristics typical of a $\mathrm{SmC}_{\gamma}{ }^{*}$ azimuthal mode ${ }^{[14]}$, but in CG50 it seems to appear first after the transition to the $\mathrm{SmC}^{*}$ phase since the azimuthal mode of the $\mathrm{SmC}^{*}$ phase (Goldstone mode) appears at the same temperature. A possible explanation is that there is some degree of phase coexistence between $\mathrm{SmC}_{\gamma}^{*}$ and $\mathrm{SmC}^{*}$. 


\section{P. JÄGEMALM et al.}

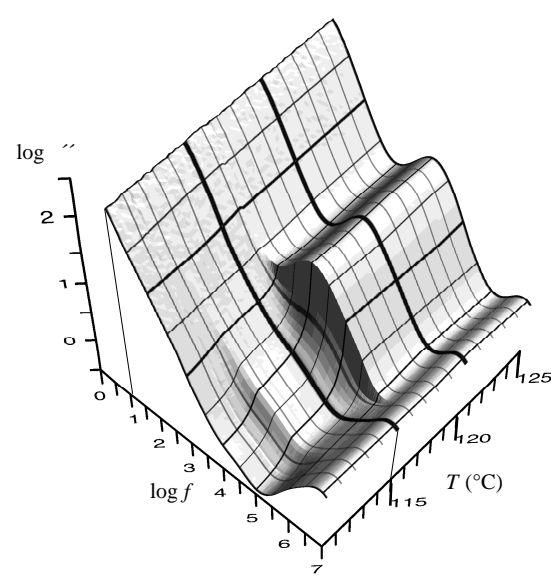

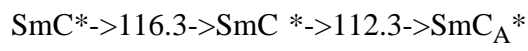

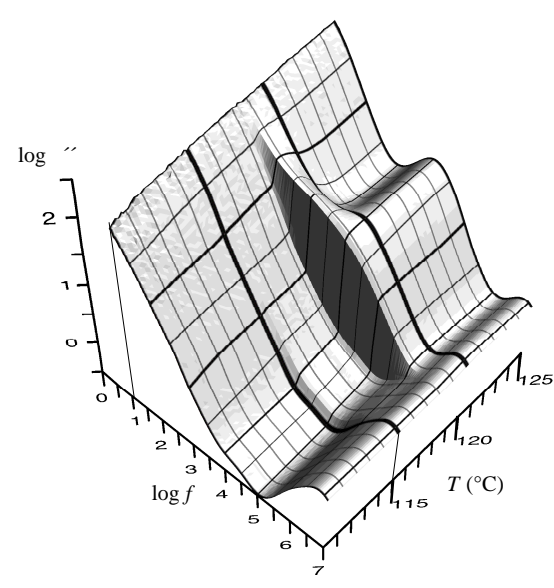

$\mathrm{SmC}_{\mathrm{A}}{ }_{->}>115.1->\mathrm{SmC}_{\gamma}{ }^{*->118.4->\mathrm{SmC}^{*}}$

FIGURE 5: 3D dielectric absorption spectra for CG50 in the vicinity of the $\mathrm{SmC}_{\gamma}{ }^{*}$ phase, on cooling (left) and heating (right) in a $50 \mu \mathrm{m}$ cell. A4 behaves similarly.

By applying a DC-bias of $0.7 \mathrm{~V} / \mu \mathrm{m}$ over the sample, the $\mathrm{SmC}_{\gamma}{ }^{*}$ phase spectra are drastically altered. The strong low-frequency absorption mentioned above now appears both on cooling and on heating, and in CG50 it is present throughout the whole $\mathrm{SmC}_{\gamma}{ }^{*}$ phase. In A4 the absorption is absent in the centre of the $\mathrm{SmC}_{\gamma}{ }^{*}$ phase, but close to the low-temperature boundary of the phase it reappears (figure 6). This supports the idea that the absorption is due to a helix-related $\mathrm{SmC}_{\gamma}{ }^{*}$ azimuthal mode. The applied DC field then seems to be enough to unwind the helix in the centre of the $\mathrm{A} 4 \mathrm{SmC}_{\gamma}{ }^{*}$ phase, but not in CG50. However, with this model it is difficult to explain the absence of the mode when no DC bias field is applied.

The $\mathrm{SmC}_{\mathrm{A}}$ * phase spectra are in both compounds without anomalies. In the high temperature end of the $\mathrm{SmI}_{\mathrm{A}}$ * phase a single absorption is observed (figure 6). However, as $f_{R}$ quickly decreases with decreasing temperature, the mode is soon covered by the ionic tail and can thus not be resolved some $10^{\circ} \mathrm{C}$ below the $\mathrm{SmC}_{\mathrm{A}}{ }^{*}-\mathrm{SmI}_{\mathrm{A}}$ * transition.

Around $45^{\circ} \mathrm{C}$ in $\mathrm{A} 4$, and $50^{\circ} \mathrm{C}$ in CG50, a transition from $\mathrm{SmI}_{\mathrm{A}}$ * to another smectic phase is observed. This is characterised by a weak absorption with an Arrhenius-like temperature dependence of $f_{R}$. We attribute this absorption to the reorientation around the molecular long axis, which can be expected to exhibit such low frequencies in a smectic 
phase with very high order. On heating, the transition to the $\mathrm{SmI}_{\mathrm{A}}$ * phase does not occur until at approximately $80^{\circ} \mathrm{C}$. The transition between these two phases thus features a hysteresis in the range of $30^{\circ} \mathrm{C}$ in both materials.

A4-Planar, cooling, $50 \mu \mathrm{m}$ cell, $\mathrm{V}=35 \mathrm{~V}$

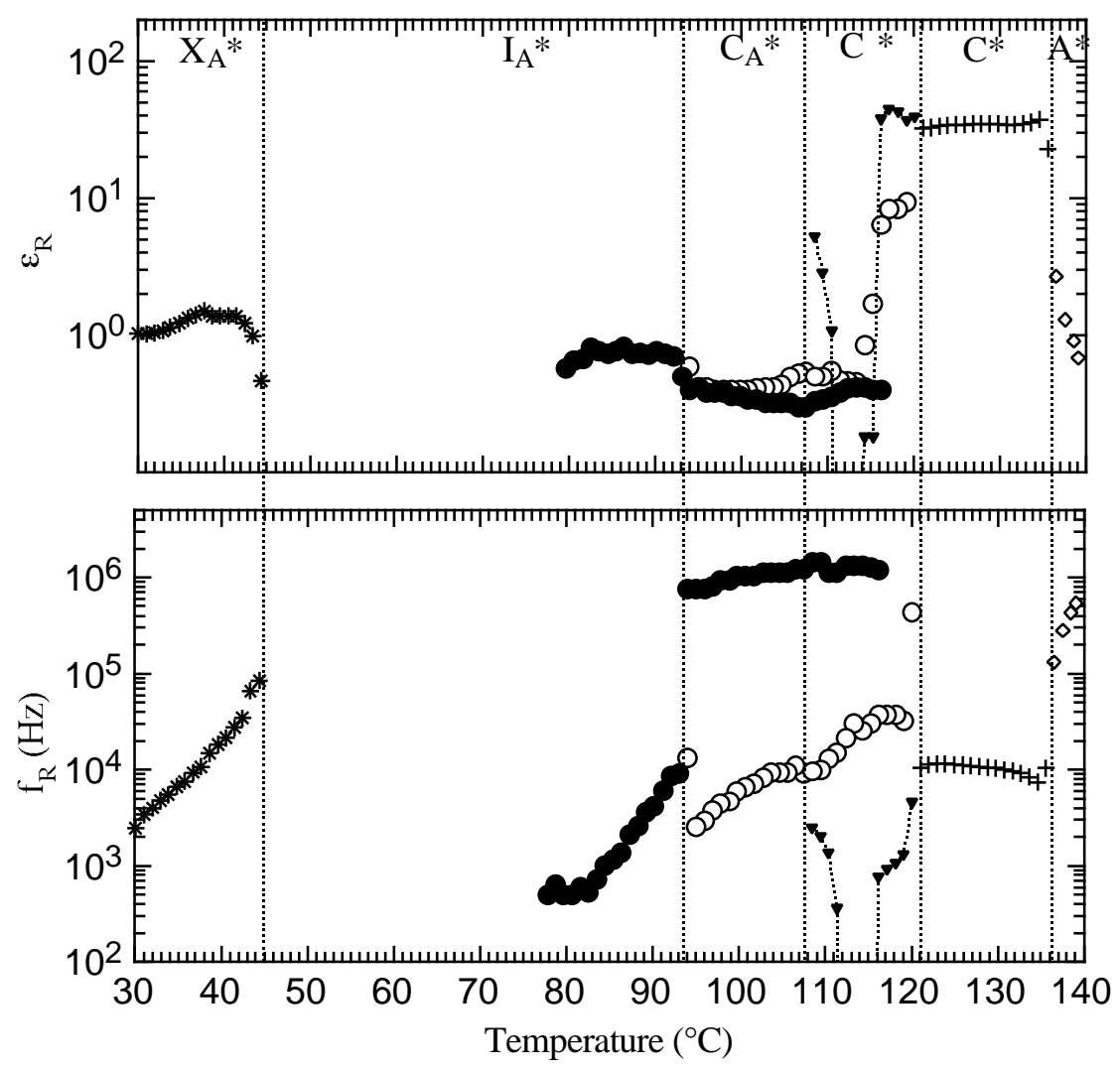

FIGURE 6: A4 in a $50 \mu \mathrm{m}$ cell on cooling with $0.7 \mathrm{~V} / \mu \mathrm{m}$ DC-bias. Cole-Cole equations have been fitted to the experimental data in order to extract the relaxation frequencies and dielectric constant contributions.

Results from thin $(2 \mu \mathrm{m})$ cells

The spectra obtained in $2 \mu \mathrm{m}$ cells differ markedly from those of the thick cells. The main difference is the absence of a $\mathrm{SmC}_{\gamma}{ }^{*}$ phase, and the very large degree of $\mathrm{SmC}^{*}$ supercooling, see figure 7. On cooling A4, the $\mathrm{SmC}^{*}$ azimuthal mode remains with undiminished intensity all the 


\section{P. JÄGEMALM et al.}

way down to $109^{\circ} \mathrm{C}$ (approximately $12^{\circ} \mathrm{C}$ below the $\mathrm{SmC}^{*}-\mathrm{SmC}_{\gamma}{ }^{*}$ transition in the $50 \mu \mathrm{m}$ cell) and then it gradually decreases through a region of phase coexistence down to the onset of the $\mathrm{SmI}_{\mathrm{A}}{ }^{*}$ phase. On heating (figure 7, right part), a weak $\mathrm{SmC}^{*}$ azimuthal mode is observed immediately after the transition from $\mathrm{SmI}_{\mathrm{A}}{ }^{*}$, and this gradually increases in intensity up to the fully developed $\mathrm{SmC}^{*}$ phase. CG50 features a similar behaviour. The large broadening of the $\mathrm{SmC}^{*}$ temperature range in thin cells is a clear indication of how surface influence promotes the $\mathrm{SmC}^{*}$ phase relative to $\mathrm{SmC}_{\gamma}{ }^{*}$ and $\mathrm{SmC}_{\mathrm{A}}{ }^{*[15]}$.
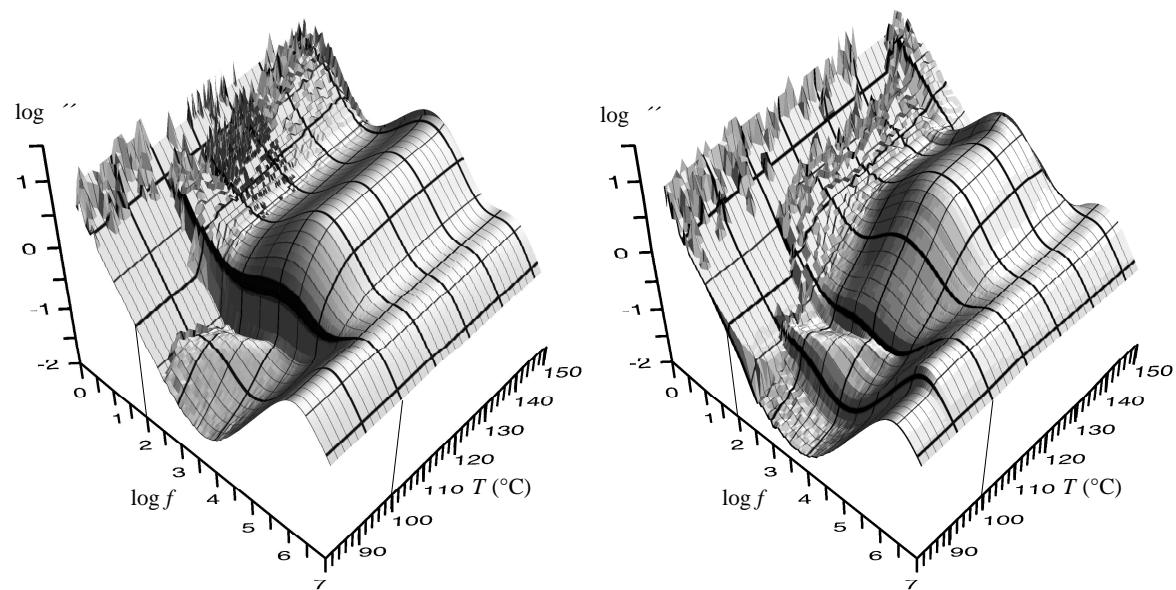

FIGURE 7: 3D dielectric absorption spectra for A4 in a $2 \mu \mathrm{m}$ cell, on cooling (left) and on heating (right). No clear sign of a $\mathrm{SmC}_{\gamma}{ }^{*}$ phase can be seen in either spectrum.

\section{CONCLUSIONS}

We have synthesised and characterised the two antiferroelectric liquid crystalline materials A4 and CG-50. Despite their non-linear molecular architecture, the materials exhibit wide $\mathrm{SmC}^{*}, \mathrm{SmC}_{\gamma}{ }^{*}$ and $\mathrm{SmC}_{\mathrm{A}}{ }^{*}$ phases. Pitch measurements and dielectric spectroscopy reveal that there is a strong hysterisis in the phase sequence on cooling and heating and that the phase temperature intervals depend on the sample thickness. In fact, the $\mathrm{SmC}_{\gamma}{ }^{*}$ phase may be totally suppressed by surface interactions in thin cells. We have also seen that a long pitch absorption, interpreted as coming from the $\mathrm{SmC}_{\gamma}{ }^{*}$ phase, is partially co-existing with the $\mathrm{SmC}^{*}$ phase. 
OPTIC AND DIELECTRIC PROPERTIES OF NOVEL AFLCs

\section{Acknowledgements}

We gratefully acknowledge financial support from the Swedish Foundation for Strategic Research.

\section{References}

[1] A.D.L. Chandani, Y. Ouchi, H. Takezoe, A. Fukuda, K. Terashima, K. Furukawa, and A. Kishi, Japan. J. Appl. Phys. Lett., 28, 1261 (1989).

[2] A.D.L. Chandani, E. Gorecka, Y. Ouchi, H. Takezoe, and A. Fukuda, Japan. J. Appl. Phys. Lett., 28, L1265 (1989).

[3] A. Fukuda, Y. Takanishi, T. Isokaki, K. Ishikawa, and H. Takezoe, J. Mater. Chem., 4, 997 (1994).

[4] D.J. Byron, L. Komitov, A.S. Matharu, I. McSherry, and R.C. Wilson, J. Mater. Chem.. 6(12), 1871 (1996).

[5] A.J.Seed, M. Hird, P. Styring, H. Gleeson and J.T. Mills, $\underline{\text { Mol. }}$ Cryst. Liq. Cryst., 299, 19 (1997).

[6] A.S. Matharu, C. Grover and R.C. Wilson, 17th International Liquid Crystal Conference, Strasbourg, France. Conference procedings (1998). To be published.

[7] K. Tamao, S. Kodama, I. Nakajima, M. Minato, and K. Suzuki, Tetrahedron, 38, 3347 (1982).

[8] A. Hassner, and V. Alexanian, Tetrahedron Lett., 4475 (1978).

[9] C.J. Booth, D.A. Dunmur, J.W. Goodby, K.S. Jaskaran, and K.J. Toyne, J. Mater. Chem., 4 (5), 747 (1994).

[10] K. Kondo, H. Takezoe, E. Kuze, Jap. J. Appl. Phys., 21, 224 (1982)

[11] F. Gouda, A. Dahlgren, S. T. Lagerwall, B. Stebler, Ferroelectrics, 178, 187 (1996)

[12] A. Dahlgren, M. Buivydas, F. Gouda, L. Komitov,S. T. Lagerwall, Liq. Cryst. 25, 553 (1998)

[13] P. Jägemalm, J. P. F. Lagerwall, A. Dahlgren, F. Gouda, L. Komitov, A. Matharu, C. Grover, to be published.

[14] See for instance Cepic, Heppke, Hollidt, Lötzsch, Zeks, Ferroelectrics, 147, 159 (1993).

[15] Rudquist et al., J. Mater. Chem., 9, 1257 (1999). 